\title{
Purification and Structure of a Novel Cysteine Proteinase Inhibitor, Strepin P-1
}

\author{
Kyoichi Ogura ${ }^{\dagger}$ Mitsuru Maeda, Masami Nagai, \\ Takaharu TANAKA, Kyosuke Nomoto* \\ and Takashi MURACHI** \\ Laboratory of Applied Microbiology, Research Center, Suntory Ltd. \\ and * Suntory Institute for Bioorganic Research, \\ Wakayamadai, Shimamoto-cho, Mishima-gun, Osaka 618, Japan \\ **Department of Laboratory Medicine, Kyoto University, \\ Faculty of Medicine, \\ Kyoto 606, Japan
}

Received September 5, 1984

\begin{abstract}
Strepin P-1, a new proteinase inhibitor, is a low molecular weight peptide isolated from the culture fluid of Streptomyces tanabeensis (SAB-934). Strepin P-1 strongly inhibited not only cysteine proteinases, calpain and papain, but also trypsin. The purification procedures included HP-20 adsorption chromatography, DEAE-cellulose, Amberlite CG-50, Sephadex LH-20 and G-25 column chromatography. The yield was $12 \mathrm{mg}$ from 8 liters of culture fluid. The proteinase inhibitor thus prepared was a peptide composed of tyrosine, valine and argininal, that reacted positively with Sakaguchi and Pauly reagents on TLC. The N-terminal amino acid, tyrosine, was blocked with an isovaleryl group and the structure was elucidated to be $N$-isovaleryl-tyrosyl-valyl-argininal. The amino acid sequence-inhibitory activity relationships of strepin P-1, leupeptin and antipain toward calpain and papain are also discussed.
\end{abstract}

Proteinous inhibitors acting on proteolytic enzymes have been isolated from the tissues of a variety of animals and plants, and their distribution, properties and biological significance have been studied (see for reviews ${ }^{1,2)}$ ). These inhibitors are peptides or glycopeptides of high molecular weight over, 5000. Recently, on the other hand, many low molecular weight peptide proteinase inhibitors were found in culture fluids of microbes. ${ }^{3 \sim 5)}$ They have been widely used in biological and biochemical studies. ${ }^{6,7)}$ It is also expected that these proteinase inhibitors can be used for diagnostic and therapeutic purposes in some diseases which may be related to aberrations of cellular enzyme activities. ${ }^{8,9)}$ One of the intracellular enzymes which are widely distributed in mammalian and avian cells is calpain [EC 3.4.22.17; $\mathrm{Ca}^{2+}$-dependent cysteine proteinase]; its biological functions are not fully understood. It may catalyze limited proteolysis of a target protein or proteins in some cells, causing significant changes in metabolic processes. ${ }^{11,12)} \mathrm{We}$ attempted to obtain any new proteinase inhibitors of calpain by screening a number of microbes.

This paper describes the isolation and structural elucidation of strepin P-1, a novel proteinase inhibitor from the culture fluid of a strain of a new Streptomyces species, Streptomyces tanabeensis (SAB-934).

\section{MATERIALS AND METHODS}

Strain and culture conditions. Strain SAB-934 isolated from a soil sample collected at the seaside in Tanabe City, Wakayama Prefecture, Japan, was identified as a new species closely related to Streptomyces galtieri from its culture characteristics and named Streptomyces

To whom correspondence should be addressed. 


\section{tanabeensis.}

The culture filtrate of Streptomyces tanabeensis was used for the preparation of a new cysteine proteinase inhibitor, strepin P-1. A seed culture was prepared aerobically at $30^{\circ} \mathrm{C}$ for 2 days in YM-medium containing $1 \%$ glucose, $0.5 \%$ polypeptone, $0.3 \%$ malt extract and $0.3 \%$ yeast extract. A seed culture $(300 \mathrm{ml})$ was inoculated into 8 liters of YM-medium and was grown at $30^{\circ} \mathrm{C}$ with vigorous aeration in a fermenter (New Brunswick Fermenter). After $48 \mathrm{hr}$ of growth, the culture fluid was harvested by centrifugation.

Assay for strepin P-1. Calpain I and calpain II were purified from porcine erythrocytes and kidney, ${ }^{13)}$ respectively. Papain, trypsin and chymotrypsin were purchased from Sigma Chemical Co., ST. Louis, MO, U.S.A. The assay mixture for calpains and papain contained, in a final volume of $2.0 \mathrm{ml}, 0.4 \%$ casein as a substrate, $50 \mathrm{~mm}$ imidazole- $\mathrm{HCl}$ buffer ( $\mathrm{pH} 7.2$ ), $5 \mathrm{~mm}$ cysteine and $1 \mathrm{~mm}$ $\mathrm{CaCl}_{2}$. The assay mixture for trypsin contained, in a final volume of $1.0 \mathrm{ml}, 0.5 \%$ casein as a substrate and $50 \mathrm{~mm}$ Tris- $\mathrm{HCl}$ buffer ( $\mathrm{pH} \mathrm{7.5).} \mathrm{The} \mathrm{assay} \mathrm{mixture} \mathrm{for} \mathrm{chymo-}$ trypsin contained, in a final volume of $2.0 \mathrm{ml}, 0.5 \%$ casein as a substrate, $100 \mathrm{~mm}$ sodium borate buffer $(\mathrm{pH} 7.6)$, $100 \mathrm{~mm} \mathrm{Na} \mathrm{CO}_{3}$ and $5 \mathrm{~mm} \mathrm{CaCl}$. For the determination of calpain activity, the protease sample was incubated at $30^{\circ} \mathrm{C}$ for $30 \mathrm{~min}$ and the reaction was stopped by adding $3.0 \mathrm{ml}$ of $5 \%$ trichloroacetic acid. The acid soluble products in the filtrate were determined by the method of Ross and Schatz ${ }^{14)}$ for which $0.4 \mathrm{ml}$ of the filtrate was diluted with the reagents to a total volume of $2.8 \mathrm{ml}$, and the absorbance at $750 \mathrm{~nm}$ was read against the blank. For the determination of papain, trypsin and chymotrypsin activity, each protease sample was incubated at $35^{\circ} \mathrm{C}$ for $20 \mathrm{~min}$, and the reaction was stopped by adding $3.0 \mathrm{ml}$ of $5 \%$ trichloroacetic acid. The absorbance at $280 \mathrm{~nm}$ of the acid soluble products in the filtrate was read against the blank. For the determination of the inhibitory activity of strepin $\mathrm{P}-1$, the inhibitor sample was preincubated in $50 \mathrm{~mm}$ imidazole- $\mathrm{HCl}$ buffer ( $\mathrm{pH}$ 7.2) with a fixed amount of calpain, papain, trypsin and chymotrypsin at $30^{\circ} \mathrm{C}$ for $5 \mathrm{~min}$, and the decrease in proteolytic activity was measured. One unit of strepin P-1 was defined as the amount of the peptide which inhibits 0.015 units of papain as calculated from the straight portion of the inhibition profile, when inhibition of papain was less than $50 \%$.

Oxidation of strepin $P-1$. The pulverised $\mathrm{KMnO}_{4}$ $(0.5 \mathrm{mg})$ was added to stirred solution of strepin P-1 $(1 \mathrm{mg})$ in $0.5 \mathrm{ml}$ of $t$-butanol- $\mathrm{H}_{2} \mathrm{O}(1: 1, \mathrm{v} / \mathrm{v})$. After $20 \mathrm{~min}$ of reaction, the excess $\mathrm{KMnO}_{4}$ was decomposed by the addition of methanol. The mixture was filtered and evaporated to dryness under reduced pressure. The residue was dissolved in $\mathrm{H}_{2} \mathrm{O}$, and then the solution was extracted with $n$-butanol.

Digestion with chymotrypsin and carboxypeptidase $P$.
For the determination of the amino acid sequence, $100 \mu \mathrm{g}$ each of untreated and oxidized strepin P-1 preparation in $500 \mu \mathrm{l}$ of buffer was digested with $50 \mu \mathrm{g}$ each of chymotrypsin (Sigma Chemical Co., St. Louis, MO, U.S.A.) and carboxypeptidase P (Peptide Institute, Protein Research Foundation, Osaka, Japan). The digestion was carried out at $40^{\circ} \mathrm{C}$ for $90 \mathrm{~min}$ in $0.05 \mathrm{M}$ sodium borate buffer $(\mathrm{pH} \mathrm{7.6)}$ with chymotrypsin or in $50 \mathrm{~mm}$ pyridine-formic acid $(\mathrm{pH}$ 2.5) with carboxypeptidase $P$, and stopped by drying under reduced pressure. The residue was dissolved in $50 \mu \mathrm{l}$ of $1 \% \mathrm{NaHCO}_{3}$, and $50 \mu \mathrm{l}$ of $0.25 \%$ dansyl chloride (Merck \& Co., Rahway, NJ, U.S.A.) was added. After an incubation for $20 \mathrm{~min}$ at $40^{\circ} \mathrm{C}$, the reaction was terminated by adding $50 \mu \mathrm{l}$ of glacial acetic acid. The reaction mixture was dried under reduced pressure, and the new N-terminal amino acid was determined on polyamide thin layer chromatography (Cheng Chin Trading Co., Taiwan) by the method of Hartley. ${ }^{15}$ )

Amino acid analysis. Strepin P-1 or oxidized strepin P-1 (approximately $5 \mu \mathrm{g}$ each) was added to $0.1 \mathrm{ml}$ of $6 \mathrm{~N} \mathrm{HCl}$, sealed under reduced pressure, and hydrolyzed at $105^{\circ} \mathrm{C}$ for $48 \mathrm{hr}$. Amino acid analysis was performed on a Hitachi model 835 amino acid analyzer. ${ }^{16)}$

Analytical procedures. The purity of the sample was examined by TLC on a Merck cellulose glass plate (DC Fertigplatten) with $n$-butanol-pyridine-acetic acid- $\mathrm{H}_{2} \mathrm{O}$ $(15: 10: 3: 12, \mathrm{v} / \mathrm{v})$. Peptides on TLC were stained with ninhydrin, Pauly, Sakaguchi, Schiff and Tollens' reagents. A Gilford model 2000-2 spectrophotometer was used for ultraviolet absorbance measurements. A Hitachi model RMU-6 mass spectrometry system was used for the measurement of the molecular weight of strepin P-1. NMR spectra of strepin P-1 were recorded with a Nicolet NT-360 NMR spectrometer for the analysis of molecular formula.

Chemicals. Leupeptin (acetyl-leucyl-leucyl-argininal) and antipain ( $N$ - $[(S)$-1-carboxy-2-phenylethyl $]$ carbamoylarginyl-valyl-argininal) were purchased from the Peptide Institute, Protein Research Foundation, Osaka, Japan. Mitsubishi Diaion HP-20 was purchased from Mitsubishi Chemical Industries Ltd., Tokyo, Japan. DEAE-cellulose (DE-23) was purchased from Whatman Ltd., Springfield, U.K. Amberlite CG-50 was the product of Rhom and Hass Ltd., U.S.A. Sephadex LH-20 and G-25 were the products of Pharmacia, Upsala, Sweden. Other reagentgrade chemicals were obtained from Wako Pure Chemicals Ltd., Osaka or Nakarai Chemicals Ltd., Kyoto, Japan.

\section{RESULTS}

\section{Purification of strepin P-1}

When Streptomyces tanabeensis (SAB-934) 
was cultured in YM-medium, the activity of strepin P-1 in the culture fluid increased rapidly during the exponential phase of cell growth and reached a maximum in the stationary phase after $40 \mathrm{hr}$ of incubation at $30^{\circ} \mathrm{C}$, followed by a rapid decline under the culture conditions used.

After removing the cells by centrifugation from the culture fluid in the stationary phase, the supernatant ( 8 liters) was applied to a column of HP-20 $(16 \times 17 \mathrm{~cm})$. The column was washed with 25 liters of water and then with 10 liters of methanol. The latter eluate, which contained strepin P-1 activity, was concentrated to $200 \mathrm{ml}$, and the concentrate was put on a column of DE-23 $\left(\mathrm{OH}^{-}\right.$form, $6 \times$ $10 \mathrm{~cm})$. The inhibitory activity appeared in the flow-through fraction and the subsequent washings with water. By this chromatography, most of the brown color of the culture fluid could be removed from the inhibitor fraction. The effluent and washings were combined and immediately applied to a column of Amberlite CG-50 $\left(\mathrm{H}^{+}\right.$form, $\left.6 \times 5 \mathrm{~cm}\right)$. The column was washed with water, followed by $0.2 \mathrm{M}$ acetic acid, until the absorbance at $250 \mathrm{~nm}$ decreased to nearly zero. The inhibitor was then eluted with $500 \mathrm{ml}$ of $1 \mathrm{M}$ pyridine-acetic acid buffer (pH 5.0) and lyophilized. The lyophilized sample was dissolved in $5 \mathrm{ml}$ of $50 \%$

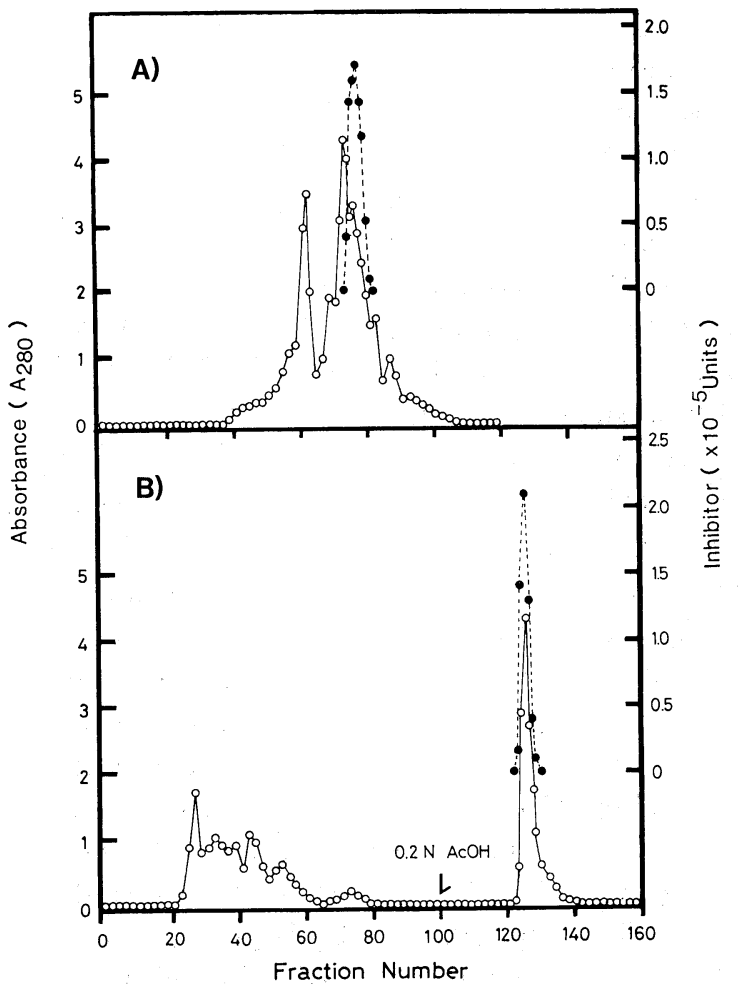

FIG. 1. Chromatography of Strepin P-1 Crude Preparation on Sephadex LH-20 (A), and Sephadex G-25 (B).

For A, a column of Sephadex LH-20 $(2.8 \times 185 \mathrm{~cm})$ was loaded with $263 \mathrm{mg}$ in $5 \mathrm{ml}$ and developed with $50 \%$ $\mathrm{MeOH}-$ acetic acid $(100: 3, \mathrm{v} / \mathrm{v})$ at a flow rate of $50 \mathrm{ml} / \mathrm{hr}$. Fractions of $10 \mathrm{ml}$ each were collected. $(\mathrm{O}-\mathrm{O})$, absorbance at $280 \mathrm{~nm}$; $(-)$ ), papain-inhibitory activity. For B, the active fractions from Sephadex LH-20 were combined and evaporated under reduced pressure. The evaporated preparation $\left(53 \mathrm{mg}\right.$ in $3 \mathrm{ml}$ of $\left.\mathrm{H}_{2} \mathrm{O}\right)$ was put on a column of Sephadex G-25 $(2 \times 45 \mathrm{~cm})$. The column was washed with $\mathrm{H}_{2} \mathrm{O}$ at a flow rate of $40 \mathrm{ml} / \mathrm{hr}$ unitl the absorbance at $280 \mathrm{~nm}$ decreased to nearly zero. At the point indicated by an arrow in the figure, $\mathrm{H}_{2} \mathrm{O}$ was supplemented with $0.2 \mathrm{M}$ acetic acid. Inhibitory activity was eluted as a single peak. Fractions of $6 \mathrm{ml}$ each were collected. $(\bigcirc-\bigcirc)$, absorbance at $280 \mathrm{~nm} ;(-\bigcirc)$, papain-inhibitory activity. 
Table I. Purification of Strepin P-1 from Culture Fluid

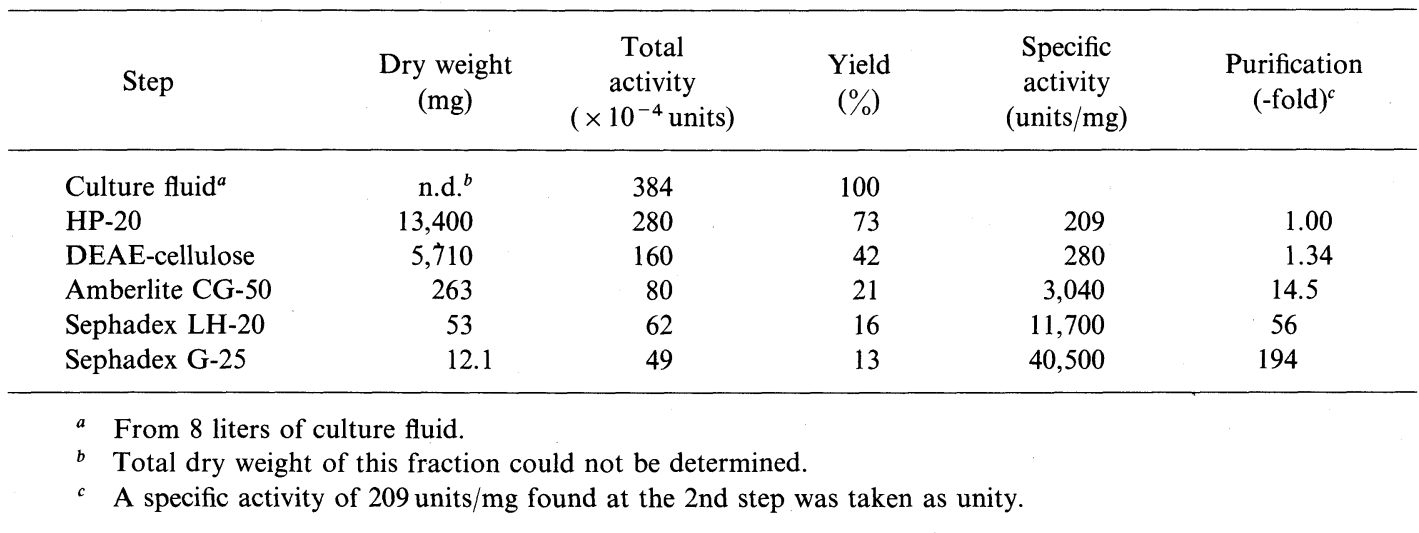

methanol-acetic acid $(100: 3, \mathrm{v} / \mathrm{v})$ and insoluble material was removed by centrifugation. The supernatant was put on a Sephadex LH20 column $(2.8 \times 185 \mathrm{~cm})$, and the column was washed with the same solvent mixture as above at a flow rate of $50 \mathrm{ml} / \mathrm{hr}$ under monitoring at $280 \mathrm{~nm}$ (Fig. 1A). Fractions which showed papain-inhibitory activity were combined and dried under reduced pressure. The residue was dissolved in $3 \mathrm{ml}$ of water and was put on a column of Sephadex G-25 $(2 \times 45 \mathrm{~cm})$ swelled in water. The column was washed with water until the absorbance at $280 \mathrm{~nm}$ decreased to nearly zero. It was then washed with $0.2 \mathrm{M}$ acetic acid, at a flow rate of $40 \mathrm{ml} / \mathrm{hr}$, which eluted the papain-inhibitory activity as a sharp and symmetrical peak (Fig. 1B). The purification procedures are summarized in Table I. Examination of the purity of strepin P-1 by TLC revealed that the residue from the active fractions (No. 125 127 in Fig. 1B) showed only one spot positive to Pauly and Sakaguchi reagents. Paper electrophoresis at $\mathrm{pH} 6.4$ also indicated the homogeneity of this preparation; it moved toward the cathode with a mobility almost equal to that of arginine.

\section{Properties and structure of strepin P-1}

The absorption spectrum of strepin P-1 in neutral $\mathrm{pH}$ solution had a maximum at $278 \mathrm{~nm}$ and a trough at $245 \mathrm{~nm}$. The infrared spectrum in $\mathrm{KBr}$ disc exhibited absorption bands at $3300 \sim 3200 \mathrm{~cm}^{-1}$ (NH and $\left.\mathrm{OH}\right), 2390 \mathrm{~cm}^{-1}$. $\left(\mathrm{CH}_{2}\right.$ and $\mathrm{CH}$ ), $1630 \mathrm{~cm}^{-1}$ (amide and gua-
Table II. Amino Acid Composition of Natural AND OXIDIZED STREPIN P-1 ${ }^{a}$

\begin{tabular}{lll}
\hline Amino acid & $\begin{array}{c}\text { Natural } \\
\text { strepin P-1 }\end{array}$ & $\begin{array}{c}\text { Oxidized } \\
\text { strepin P-1 } \\
\text { with } \mathrm{KMnO}_{4}\end{array}$ \\
\hline Valine & $1.00(1)$ & $1.00(1)$ \\
Tyrosine & $0.996(1)$ & $0.946(1)$ \\
Arginine & $0 \quad(0)$ & $0.873(1)$ \\
\hline
\end{tabular}

a All values were calculated assuming one valine residue present per molecule of strepin $\mathrm{P}-1$.

nidium), $1540 \mathrm{~cm}^{-1}$ (amide II) and $1500 \mathrm{~cm}^{-1}$ (phenyl). Strepin P-1 also gave positive color reaction on TLC to Pauly, Sakaguchi and Tollens' reagents, but negative to ninhydrin reagent. The amino acid analysis of untreated strepin P-1 showed equal amounts of valine and tyrosine, while after $\mathrm{KMnO}_{4}$-oxidation one molecule of arginine appeared (Table II).

The molecular formula of strepin P-1 was assigned as $\mathrm{C}_{25} \mathrm{H}_{40} \mathrm{O}_{5} \mathrm{~N}_{6}$ (M.W. 504) on the basis of elemental analysis. Anal. Calcd. for $\mathrm{C}_{25} \mathrm{H}_{40} \mathrm{O}_{5} \mathrm{~N}_{6}: 4 \mathrm{H}_{2} \mathrm{O} ; \mathrm{C}, 52.07: \mathrm{H}, 8.73: \mathrm{N}$, 14.75; Found, C, 52.37: H, 8.51: N, 14.82 and the field desorption mass spectrum (FD-MS) $\left[m / z 505(\mathrm{M}+1)^{+}\right]$. The melting point and specific rotatory power of strepin $\mathrm{P}-1$ were: $\mathrm{mp} 184 \sim 186^{\circ} \mathrm{C}$ (decomposition) and $[\alpha]_{\mathrm{D}}^{24}$ $-10.9^{\circ}\left(c=0.14, \mathrm{H}_{2} \mathrm{O}\right)$.

From these results, we concluded that strepin P-1 is a tripeptide containing tyrosine, valine and argininal, and that the $\mathrm{N}$-terminal amino group in the peptide must be blocked. 
Table III. ${ }^{1}$ H-NMR Spectroscopic Data for Strepin P-1

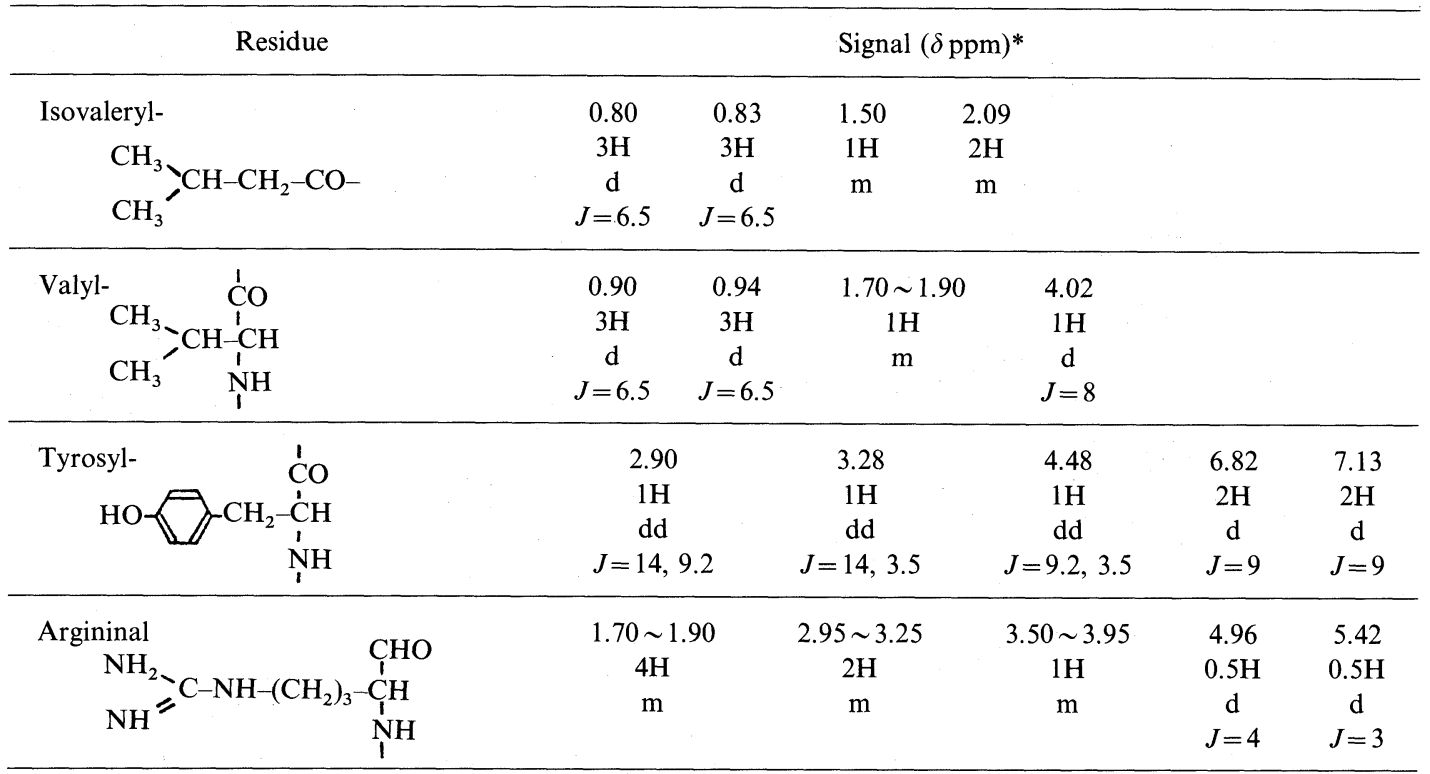

* Chemical shifts were measured from internal DSS.

The ${ }^{1} \mathrm{H}$-NMR spectrum of strepin $\mathrm{P}-1$ in $\mathrm{D}_{2} \mathrm{O}$ was analyzed by comparison with that of the known proteinase inhibitor, leupeptin. The ${ }^{1} \mathrm{H}-\mathrm{NMR}$ spectrum indicated the presence of equimolar amounts of isovaleryl, tyrosine, valine and argininal moieties, and provided further evidence for the existence of hydrate and carbinolamine forms in the argininal moiety (Table III); this had been shown to hold for leupeptin. ${ }^{17)}$

The amino acid sequence of strepin P-1 was determined using oxidized strepin $\mathrm{P}-1$ as the starting material. After digestion with chymotrypsin and dansylation, the appearance of dansyl-valine was confirmed on polyamide TLC. Furthermore, the result of carboxypeptidic cleavage suggested that the carboxylterminal sequence of the oxidized strepin P-1 should be valyl-arginine; hence, tyrosyl-valylargininal for the natural strepin P-1 (Fig. 2).

\section{Reactivity}

The purified strepin P-1 inhibited calpain I, calpain II and papain strongly (Fig. 3). The doses of strepin P-1 required for $50 \%$ inhibition, $\mathrm{ID}_{50}$, toward calpain I from porcine

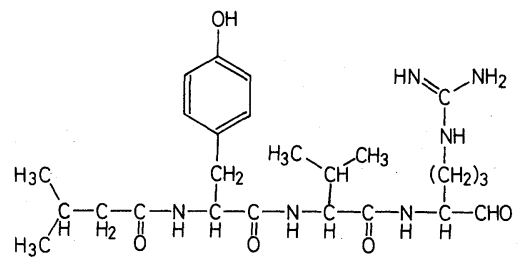

Fig. 2. Chemical Structure of Strepin P-1.

erythrocytes, calpain II from porcine kidney and papain under the conditions employed were $0.38 \mu \mathrm{g} /$ tube, $0.56 \mu \mathrm{g} /$ tube and $0.20 \mu \mathrm{g} /$ tube, which corresponded to $7.5 \times 10^{-7} \mathrm{M}$, $1.1 \times 10^{-6} \mathrm{M}$ and $2.0 \times 10^{-7} \mathrm{M}$, respectively. As shown in Fig. 3, ID $_{50}$ values of leupeptin were $7.0 \times 10^{-7} \mathrm{M}$ for calpain I, $9.4 \times$ $10^{-7} \mathrm{M}$ for calpain II and $2.1 \times 10^{-6} \mathrm{M}$ for papain. $\mathrm{ID}_{50}$ values of antipain were $4.3 \times$ $10^{-6} \mathrm{M}$ for calpain I, $9.9 \times 10^{-7} \mathrm{M}$ for calpain II and $6.0 \times 10^{-7} \mathrm{M}$ for papain. Strepin P-1 also inhibited trypsin with an $\mathrm{ID}_{50}$ value of $2.0 \times$ $10^{-6} \mathrm{M}$ (graphic data not shown).

\section{DISCUSSION}

The primary object of this study was to 


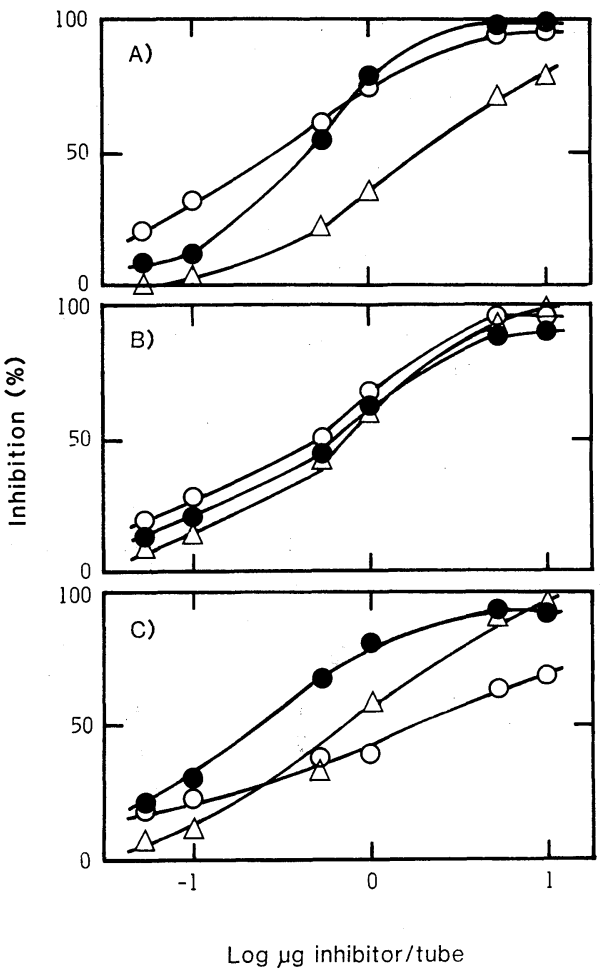

FIG. 3. Effects of Strepin P-1, Leupeptin and Antipain on Calpain I (A), Calpain II (B) and Papain (C).

Each tube contained 0.33 unit of calpains I and II, or 0.015 unit of papain. After preincubation with various amounts of each inhibitor at $30^{\circ} \mathrm{C}$ or $35^{\circ} \mathrm{C}$ for $5 \mathrm{~min}$, the remaining activity was assayed. ( -0$)$, streptin $\mathrm{P}-1 ;(\mathrm{O}-\mathrm{O})$, leupeptin; $(\triangle-\triangle)$, antipain.

isolate some novel inhibitor acting on calpain from the culture fluid of certain microbes. We were able to isolate strepin P-1, which has a structure unprecedented among the known proteinase inhibitors from mictrobes. However, the specificity spectra of strepin P-1 toward several cysteine and non-cysteine proteinases were not so unusual as we had expected: it did inhibit calpain strongly, but also papain fairly strongly and even trypsin.

The presence of a C-terminal argininal residue is, of course, responsible for its inhibition of trypsin. Both leupeptin and antipain also contained argininal residues at the carboxyl end, ${ }^{17,18)}$ which may be recognized as P1 residue by the enzyme, if one uses the subsite notation originated by Schechter and Berger. ${ }^{19)}$ Trypsin may not be influenced pro- foundly by the nature of $\mathrm{P} 2$ residue, whereas the latter residue plays an important role in determining specificity of cysteine proteinases. Papain favors a valine at $\mathrm{P} 2$ position over a leucine residue, while the reverse is true with calpains, both $\mathrm{I}$ and II. ${ }^{20)}$ The ID $_{50}$ values found in the present study (Fig. 3) are in full accord with these known orders of preference. Thus, strepin P-1 as well as antipain, which have a valine residue at $\mathrm{P} 2$ position, inhibited papin more strongly than calpain, while leupeptin with a leucine at $\mathrm{P} 2$ position inhibited calpain more strongly than papain.

The presence of a tyrosine residue at P3 position was totally unexpected, because none of the previously known proteinase inhibitor peptides contained tyrosine. ${ }^{17,18,21)}$ Because of these novelties, we conducted rather thorough structural studies on strepin P-1, and all the data (Fig. 2, Tables II and III) confirmed the unique structure of this new inhibitor as $N$ isovaleryl-tyrosyl-valyl-argininal. A synthetic peptide based on this proposed amino acid sequence, is fully active as the cysteine proteinase inhibitor. Further studies on the mechanism of inhibition and biosynthesis of strepin P-1 are to be conducted in comparison with those of leupeptin and antipain. ${ }^{3)}$

Acknowledgment. We thank Dr. Ichiro Kubota for performing the amino acid analysis and Dr. Naoki Higuchi for his valuable comments.

\section{REFERENCES}

1) R. Vogel, I. Trautschold and E. Werle, "Natural Proteinase Inhibitor," Academic Press, New York, N.Y., 1968.

2) M. Laskowski, Jr. and I. Kato, Ann. Rev. Biochem., 49, 593 (1980).

3) H. Umezawa, "Methods in Enzymology," Vol. 45, ed. by L. Lorand, Academic Press, New York, N.Y., 1976, p. 678.

4) T. Aoyagi, "Bioactive Peptides Produced by Microorganisms," ed. by H. Umezawa, T. Shibata and T. Takita, Kodansha Scientific Press, Tokyo, 1978, p. 129.

5) S. Murao, Nippon Nôgeikagaku Kaishi, 55, 503 (1981).

6) C. Devaux, P. Corvol and J. Menard, Biochim. Biophys. Acta, 359, 421 (1974). 
7) K. Murakami and T. Inagami, Biochem. Biophys. Res. Commun., 62, 757 (1975).

8) P. Libby and A. L. Goldberg, Science, 199, 534 (1978).

9) R. P. Miller, C. J. Poper, C. W. Wilson and E. Devoit, Biochem. Pharmacol., 21, 2941 (1972).

10) T. Aoyagi, M. Ishizuka, T. Takeuchi and $\mathrm{H}$. Umezawa, Japan. J. Antibiotics Suppl., 30, s-121 (1977).

11) T. Murachi, "Calcium and Cell Function," Vol. 4, ed. by W. Y. Chung, Academic Press, New York, N.Y., 1983, p. 377.

12) T. Murachi, Trends in Biochem. Sci., 8, 167 (1983).

13) A. Kitahara, T. Sakai, T. Kikuchi, N. Yumoto, N. Yoshimura, M. Tanaka and T. Murachi, $J$. Biochem., 95, 1767 (1984).
14) E. Ross and G. Schatz, Anal. Biochem., 54, 304 (1973).

15) B. S. Hartley, Biochem. J., 119, 805 (1970).

16) H. Speckman, H. W. Stein and S. Moore, Anal. Chem., 30, 1190 (1958).

17) T. Aoyagi, T. Takeuchi, A. Matsuzaki, K. Kawamura, S. Kondo, M. Hamada, K. Maeda and H. Umezawa, Japan. J. Antibiotics, 22, 283 (1969).

18) H. Suda, T. Aoyagi, M. Hamada, T. Takeuchi and H. Umezawa, Japan. J. Antibiotics, 25, 263 (1972).

19) I. Schechter and A. Berger, Biochem. Biophys. Res. Commun., 27, 157 (1967).

20) T. Sasaki, T. Kikuchi, N. Yumoto, N. Yoshimura and T. Murachi, J. Biol. Chem., 259 in press.

21) T. Shin-Watanabe, K. Fukuhara and S. Murao, Tetrahedron, 38, 1775 (1982). 